\title{
Caries dental y salud oral en poblaciones coloniales de Mendoza (Argentina) durante los siglos XVIII-XIX
}

\author{
Dental caries and oral health in colonial populations of Mendoza \\ (Argentina) during the XVIII-XIX centuries
}

\author{
P. Sebastián Giannotti ${ }^{1}$, Daniela A. Mansegosa ${ }^{2}$ y Horacio D. Chiavazza ${ }^{3}$
}

\begin{abstract}
Resumen
Este trabajo examina la presencia de caries dental en una muestra de esqueletos adultos provenientes de excavaciones llevadas a cabo en el sector que ocupó el templo colonial de San Francisco-La Caridad (siglos XVIII-XIX) en el Área Fundacional de la ciudad de Mendoza (Argentina). Se evalúa la frecuencia, distribución y localización de lesiones cariosas en la dentición anterior y posterior de dos submuestras (dientes de entierros primarios y secundarios). Cada submuestra correspondería a sectores sociales con diferente estatus. La prevalencia de caries resultó similar entre ambos conjuntos, aunque la distribución y localización de las lesiones presentó diferencias. Estas fueron interpretadas en relación con información histórica, etnohistórica y arqueológica sobre la dieta y prácticas de preparación de alimentos y de higiene oral de las poblaciones coloniales de la ciudad de Mendoza, sugiriendo estilos de vida diferentes entre los distintos sectores socioeconómicos.
\end{abstract}

Palabras claves: caries, dieta, estatus, templos coloniales, Mendoza.

\begin{abstract}
This work studies the presence of dental caries in a sample of adult skeletons recovered from excavations carried out in the colonial temple of San Francisco-La Caridad (18th-19th centuries) in the Foundational Area of Mendoza (Argentina). Frequency, distribution and location of carious lesions in the anterior and posterior dentition of two sub-samples (teeth of primary and secondary burials) are evaluated. Each subsample could correspond to social sectors with different status. The prevalence of caries was similar among social groups, although some differences in the distribution and location of the lesions were observed. These were interpreted in relation to historical, ethnohistorical and archaeological information on diet, food preparation practices, and oral hygiene of the colonial populations from Mendoza, suggesting different lifestyles among the different socioeconomic sectors.
\end{abstract}

Keywords: caries, diet, status, colonial temples, Mendoza.

Recibido: 7 diciembre 2016. Aceptado: 15 marzo 2017

1 CONICET, Laboratorio de Arqueología Histórica y Etnohistoria, Facultad Filosofía y Letras, Universidad Nacional de Cuyo. Centro de investigaciones Ruinas de San Francisco. CC 5500. ARGENTINA. Email: pablosebastiangiannotti@gmail.com

2 CONICET, Laboratorio de Arqueología Histórica y Etnohistoria, Facultad Filosofía y Letras, Universidad Nacional de Cuyo. Centro de Investigaciones Ruinas de San Francisco. CC 5500. ARGENTINA. Email: mansegosad@yahoo.com.ar

3 Profesor Titular, Instituto de Arqueología y Etnología, Laboratorio de Arqueología Histórica y Etnohistoria, Facultad Filosofía y Letras, Universidad Nacional de Cuyo. Centro de Investigaciones Ruinas de San Francisco. CC 5500. ARGENTINA. Email: hchiavazza@ gmail.com 


\section{Introducción}

Los estudios bioarqueológicos de las poblaciones históricas del norte de la provincia de Mendoza (Argentina) están orientados a caracterizar las condiciones de salud y estilos de vida de los diversos grupos socioeconómicos, aspectos poco indagados por la historiografía local y evaluados casi en exclusividad por la arqueología (p.e., Chiavazza, 2005; Mansegosa y Chiavazza, 2010; Giannotti, 2016b; Mansegosa, 2016). Estos estudios, abordados desde una perspectiva biocultural, se han enfocado en evaluar cómo las diferentes condiciones de vida impactan en la salud de las poblaciones, generando distribuciones desiguales de los indicadores de salud (Leatherman y Goodman, 1997).

La hipotética procedencia social de los entierros inhumados en los templos coloniales de la ciudad colonial de Mendoza han permitido ordenar heurísticamente las muestras bioantropológicas (Chiavazza, 2005). Esto permitió detectar una relación entre la procedencia social de los entierros y la frecuencia y distribución de indicadores de estrés metabóliconutricional, estrés funcional y procesos infecciosos específicos e inespecíficos (Chiavazza, 2005; Mansegosa y Chiavazza, 2010; Mansegosa, 2015a, 2015b, 2016; Giannotti, 2016).

La dieta y salud oral de las poblaciones coloniales de Mendoza es una línea de estudio que está siendo recientemente profundizada. Frente a la escasa y genérica información histórica y etnohistórica disponible, los últimos trabajos bioarqueológicos han detectado diferencias en la distribución de bioindicadores orales de dieta y salud entre grupos sociales (Chiavazza, Mansegosa y Gil, 2015; Mansegosa, 2015a, 2016) que, si bien lograron constatar y/o contradecir la información histórica y etnohistórica, aún no han logrado profundizar en los factores que inciden en su aparición y desarrollo. En este sentido, el estudio de un indicador de dieta y salud oral como es la caries dental permitiría no solo evaluar su impacto en distintos grupos socioeconómicos, sino también indagar las etiologías que están actuando como medio para reconstruir estilos de vida de los diversos estamentos que componían la sociedad colonial de Mendoza.
La caries es un indicador bioarqueológico de salud oral y alimentación que contribuye al conocimiento de modos de vida en poblaciones del pasado (Larsen, 2002). La misma, es definida como una desmineralización progresiva del esmalte, cemento y dentina, producida por actividad microbiana sobre la superficie del diente (Larsen, 2015; Menéndez, 2016; Juengst et al., 2016). Se debe a la actividad de algunas bacterias (fundamentalmente Streptococus mutans) de la placa que, a través de la fermentación de carbohidratos que son ingeridos en la dieta, eliminan ácidos orgánicos que destruyen el tejido dental (Hillson, 2008). En la mayoría de los casos, la caries es un proceso muy lento y progresivo, con la alternancia de fases de estabilidad y actividad durante muchos ańos (Pino y Ten Bosch, 1996, citado en Hillson, 2008).

Las tasas de caries en una población son el resultado de factores fisiológicos, conductuales y ambientales, que actúan de manera sinérgica, compleja y dinámica. Dichos factores se agrupan según la dieta (consistencia/textura, capacidad de fermentación y presencia de carbohidratos, azúcar y almidón), desarrollo dental (edad de erupción dental, defectos de desarrollo como hipoplasia o maloclusión, dureza del esmalte o composición), enfermedades y medicaciones suministradas (xerostimía por envejecimiento, medicaciones múltiples, radiación o quimioterapia, síndrome de Sjögren, entre otros) (Hubbe et al., 2012; Turner, 2013). A estos grupos de factores se le suman otros de tipo fisiológico (tasas de flujo salival, composición bioquímica de la saliva, ecología oral y microbiología, tipo y niveles de clases de hormonas según la pubertad, el embarazo, la menopausia, entre otras) y de comportamiento (método de preparación de la comida, frecuencia del consumo, higiene oral y elección del alimento) (Lukacs y Largaespada, 2006, p. 551).

El objetivo del presente trabajo es evaluar la frecuencia y distribución de lesiones cariosas ${ }^{4}$ en una muestra de individuos adultos de diferente procedencia

4 El término caries o caries dental hace alusión al proceso de la enfermedad, mientras que lesiones cariosas (carious lesions) son las manifestaciones detectables macroscópicamente de dicho proceso de desmineralización de los tejidos del diente (Hillson, 2001, 2008; Larsen, 2015). 
socioeconómica que se inhumaron entre los siglos XVIII y XIX en el templo franciscano (luego de La Caridad) de la ciudad de Mendoza, denominado Punto Arqueológico San Francisco-La Caridad (en adelante PASF-LC). Basados en los postulados de la procedencia socioeconómica de los entierros, se espera encontrar diferencias en la frecuencia y distribución de lesiones entre grupos sociales. Los resultados serán discutidos en función de la información histórica, etnohistórica y arqueológica, con la finalidad de indagar sobre las etiologías que pueden explicar el desarrollo de caries dental entre los grupos y así continuar aportando información a los diversos estilos de vida.

\section{Antecedentes bioarqueológicos del Sitio Área Fundacional}

Los patrones de inhumación en los templos católicos coloniales de la ciudad de Mendoza (siglos XVI-XIX) respondían a una normativa rigurosa de la Iglesia católica. El difunto debía enterrarse en el interior o exterior del templo dependiendo de su capacidad económica (y la de su familia) para ocupar lugares de mayor o menor preeminencia (Ariès, 2000; Chiavazza, Mansegosa, Gámez Mendoza y Giannotti, 2015). Partiendo de esta premisa, la segregación espacial de los entierros constituye el criterio principal que permite conocer la posición socioeconómica de la cual proviene el difunto, y elaborar un modelo referido a la procedencia social de las muestras analizadas (Chiavazza, 2005, 2008).

Los resultados de los análisis bioarqueológicos realizados en muestras excavadas en cinco templos del sector fundacional de la ciudad de Mendoza reflejan diferentes condiciones de salud de los individuos según el sector de entierro, lo que apoya inicialmente la propuesta. Los individuos de sectores sociales con mayores recursos y enterrados en espacios con mayor significación registran menores tasas de indicadores de estrés inespecífico (hipoplasias de esmalte dental, hiperostosis porótica y cribra orbitalia tanto en adultos como en subadultos) y lesiones traumáticas en la columna vertebral y manos (Chiavazza, 2005; Mansegosa y Chiavazza, 2010; Giannotti 2016a; Mansegosa 2016).
Los estudios de dieta y salud oral a partir del análisis dental de individuos articulados realizados hasta la fecha provienen de dos templos coloniales del Sitio Área Fundacional (PA Ruinas de San Francisco y PA San Francisco-La Caridad). Los análisis se centraron en relevamiento de caries, abscesos, pérdida de dientes antemortem, periodontitis y desgaste del esmalte dental. Los resultados, además de dar cuenta de una composición de dieta mixta, reflejan tendencias diferentes en la frecuencia de estos bioindicadores dentales entre entierros del interior y exterior de los templos. Los individuos del interior presentan los valores más altos de caries dental, mayor pérdida antemortem de dientes y menor tasa de desgaste dental en relación a los entierros del exterior. Estos resultados reflejarían estilos de vida diferentes entre los sectores de mayores recursos (inhumados al interior de los templos) y aquellos de menores recursos (inhumados al exterior de ellos) (Chiavazza, 2005; Mansegosa, 2015a). Los resultados y discusiones generados en estos trabajos han estado enfocados en detectar tendencias generales que denoten el impacto desigual de las condiciones materiales de vida en la salud. Sin embargo, no han estado orientados a indagar cómo operan las etiologías múltiples en bioindicadores concretos de dieta y salud oral. Y tampoco se ha comparado estos resultados con la información obtenida en muestras que presentan mayor complejidad metodológica, como pueden ser los entierros secundarios, los cuales representan el volumen osteológico más importante de las poblaciones exhumadas en templos católicos coloniales de la ciudad de Mendoza.

Teniendo como punto de partida las tendencias de estos trabajos previos, se pretende avanzar en el estudio de la dieta y salud oral a partir del análisis de la caries dental con un abordaje metodológico específico que permitirá discutir la etiología múltiple y compleja en una dimensión social.

\section{Dieta e higiene oral: información histórica, etnohistórica y arqueológica}

La información histórica, etnohistórica y arqueológica sostiene que la dieta de los habitantes de la ciudad colonial de Mendoza se caracterizó por ser variada, rica en proteínas y carbohidratos, resultado 
de una economía fuertemente agrícola. Las verduras y frutas eran productos abundantes, accesibles y de calidad (Giamportone, 1998). Las frutas consistían en sandías, higos, uvas, duraznos, melones, ciruelas, manzanas, peras, damascos, frutillas, naranjas, limones, nueces y almendras; mientras que las verduras, hortalizas y granos comprendían zapallos, porotos, papas, coles, cebollas, olivos, maíz, trigo y cebada (Calderón, 1967; Comadrán Ruiz, 1968; Coria, 1988). En las familias de menores recursos, la historiografía habla de una dieta básica centrada en el maíz (empleado en numerosas comidas) junto a diversos granos aderezados en forma de guisos y puchero con distintos vegetales (Cano Rossini, 1996, 76). Sin embargo, los análisis isotópicos realizados sobre muestras bioarqueológicas del Área Fundacional destacan una fuente de energía obtenida principalmente a partir de recursos C3 (trigo y cebada) (Chiavazza, Mansegosa y Gil, 2015), cuestionando el consumo de maíz sostenido en las fuentes históricas. El registro arqueobotánico de la antigua ciudad, por otra parte, está compuesto principalmente por granos de cereales europeos (trigo y avena), vid, olivo y sobre todo duraznero, mientras que en sectores más alejados y periféricos, como por ejemplo el sitio Tulumaya, abunda el algarrobo (Prosopis sp.) (Chiavazza y Mafferra, 2007; Mafferra, 2016).

Las industrias derivadas, vinculadas con el procesamiento, fueron un componente sumamente importante en el consumo y la comercialización. Entre los productos más destacados se pueden mencionar las mermeladas de frutas, las frutas secas (uvas, higos y duraznos), la harina de trigo y bebidas alcohólicas como el vino y el aguardiente (Calderón, 1967). La sociedad mendocina tenía, en palabras de Cano Rossini (1967), gran apetencia por lo dulce, facilitado por la abundancia de frutas en los huertos familiares; lo que dio origen a la industrialización de mermeladas en escala doméstica. La industria harinera también tuvo una presencia importante en la economía local y la dieta mendocina. Desde el siglo XVII (hasta mediados del siglo XIX) se registra la instalación y el crecimiento cuantitativo de establecimientos molineros de cereales (especialmente de trigo) que permitieron el abastecimiento interno de harinas. Las harinas producidas eran de un grano grueso a mediano en general, por lo que influía en la calidad de los productos derivados que se elabo- raban, principalmente el pan (Figueroa, 2006). Este alimento, componente importante durante la Colonia, era producido y consumido en escala doméstica debido a que la harina de las panaderías estaban bajo permanente sospecha de encontrarse en mal estado (Cano Rossini, 1996). Arqueológicamente, los restos carpológicos indican una incorporación temprana de trigo y avena, aun en lapsos inmediatamente previos a la conquista y colonización efectiva del territorio que luego ocuparía la ciudad (Chiavazza y Mafferra, 2007). En cuanto a la bebida, se consumía vino, aguardiente, chicha (producto derivado del primer estadio de fermentación de la uva) y licores (Cano Rossini, 1996).

El consumo de animales se basaba en peces (trucha criolla y bagre), ganado vacuno, cabra, aves (p.e., pollo) y de caza (liebre, perdiz, quirquincho y guanaco en las afueras de la ciudad) (Cano Rossini, 1996; Prieto, 2000 [1983]). En este sentido, el estudio arqueofaunístico confirma esta tendencia en la cocina de contextos que remontan al lapso comprendido entre los siglos XV y XVI (García Llorca, 2003; Ortega et al., 2006; Araujo, 2015). Durante tiempos prehispánicos tardíos, se observa un importante consumo de pescado entre las poblaciones originarias, que se mantiene significativamente hasta el siglo XVIII según la documentación y el registro ictioarqueológico (Chiavazza, 2013). La carne vacuna se preparaba asada, hervida, en puchero o guisos (Coria, 1988; Cano Rossini, 1996; Prieto, 2000 [1983]). Sin embargo, Calderón (1967) dice que el ganado vacuno antes de 1810 generalmente no alcanzaba para las necesidades de la población. Desconocemos cómo impactaba esa limitada disponibilidad de carne vacuna en relación a los sectores socioeconómicos altos y bajos. Por otro lado, la carne vacuna y la leche recibían críticas por su mala calidad (carne cansada o dura y leche aguada) (Cano Rossini, 1996).

El comercio a larga distancia permitió el acceso de alimentos más refinados consumidos por los sectores socioeconómicos altos, tales como el café, té, chocolate y azúcar (Cano Rossini, 1996; Prieto, 2000 [1983]). Además, la alta sociedad mendocina consumía frecuentemente productos alimenticios ricos en azúcares en diversos eventos sociales tales como tertulias, bailes y cenas (Giamportone, 1998). 
Por otra parte, la información referida a la higiene oral (hábitos, cuidados y tratamientos terapéuticos) de las poblaciones coloniales de Mendoza es menos conocida que la dieta. Como en todas las colonias españolas en América, las prácticas profesionales médicas que atendían las enfermedades orales estaban dadas por la farmacopea de las boticas, la experiencia práctica de cirujanos certificados y barberos que hacían extracciones dentales y drenaban abscesos (Cruz-Coke, 1995, citado en Valdenegro et al., 2014). En la ciudad de Mendoza entre el siglo XVIII y XIX, sabemos de la existencia de prácticas odontológicas mediante las cuales se realizaban extracciones de dientes y drenajes de abscesos (realizados fundamentalmente por los barberos) a partir de la presencia de profesionales autorizados a tal fin, la existencia de registros que dan cuenta de la disponibilidad de instrumental para su tratamiento y la existencia de boticas (Coni, 1897; Semorile et al., 1988; Cano Rossini, 1996).

Los hábitos de higiene oral durante los siglos XVIII y XIX son prácticamente desconocidos. La escasa información histórica es de tipo indirecta (sobre la higiene personal general). Por ejemplo, los viajeros extranjeros que pasan por la ciudad a fines del siglos XVIII y comienzos del XIX se refieren a los escasos o nulos hábitos de higiene personal de los sectores más populares, a diferencia de los grupos de la alta sociedad, aunque ninguno de ellos menciona datos relacionados específicamente con la higiene oral (Cano Rossini, 1996, pp. 95-97; Giamportone, 1998). La cultura material hallada en contextos arqueológicos en el siglo XIX en otros puntos del Virreinato del Río de La Plata da cuenta de la existencia de objetos de higiene dental (como es el cepillo de dientes) de forma escasa y limitada a algunas familias de las élites locales (Faire, 2003; Camino, 2013). Cabe destacar que hasta las primeras décadas del siglo pasado el cepillo de dientes era un bien extremadamente raro entre la población mundial (Mattick, 1998, citado en Gaitán Ammann, 2001-2002). En función de esta información general, podemos suponer que la posibilidad que tuvo la élite mendocina para acceder a productos importados europeos para el cuidado de los dientes fue escasa, lo que no quiere decir que no haya existido algún otro hábito de cuidado oral entre los diferentes grupos sociales.

\section{Materiales y métodos}

La muestra dental utilizada en este trabajo procede de excavaciones realizadas en PALC-SF, ubicado a $200 \mathrm{~m}$ de la plaza central del Área Fundacional de la ciudad de Mendoza (Figura 1).

El templo fue un espacio de inhumación cuyas procedencias socioeconómicas se pueden diferenciar cronológicamente de acuerdo con la orden religiosa que lo gestionó. La fundadora fue la Orden de San Francisco de Asís (1711-1787), que ocupó el interior del templo para inhumar difuntos provenientes de familias con mayores recursos socioeconómicos. La segunda ocupación correspondió a la Hermandad de La Caridad (1803-ca. 1830), la cual destinó esos mismos espacios para inhumar a difuntos provenientes de grupos con menores recursos socioeconómicos e incluso sujetos ajusticiados (Verdaguer, 1931). Es decir, en un mismo edificio y durante un lapso temporal de aproximadamente 120 años (entre 1711 y la década de 1830), dos agrupaciones religiosas inhumaron consecutivamente personas que, hipotéticamente, experimentaron condiciones de vida diferentes.

A partir de las excavaciones arqueológicas, se registraron dos niveles de entierro: un nivel inferior compuesto por entierros primarios y otro superior compuesto por entierros secundarios de huesos mezclados y desagregados. Los mismos estaban asociados a clavazones de metal de ataúd, ajuar funerario (medallas y crucifijos), botones de metal y perdigones de armas de fuego, sumado a restos constructivos del templo destruido por el terremoto de 1861. Las características tipológicas de los restos arqueológicos sugieren una cronología relativa que coincide con el período de ocupación del templo, entre el siglo XVIII y principios del XIX.

Basados en el registro estratigráfico de contextos funerarios del Sitio Área Fundacional (Chiavazza, 2005; Chiavazza, Mansegosa, Gámez Mendoza y Giannotti, 2015), se sostiene una cronología relativa de los individuos inhumados según los tipos de entierros: los primarios corresponden mayormente a inhumaciones tardías, mientras que los entierros secundarios a inhumaciones más tempranas. Estos 


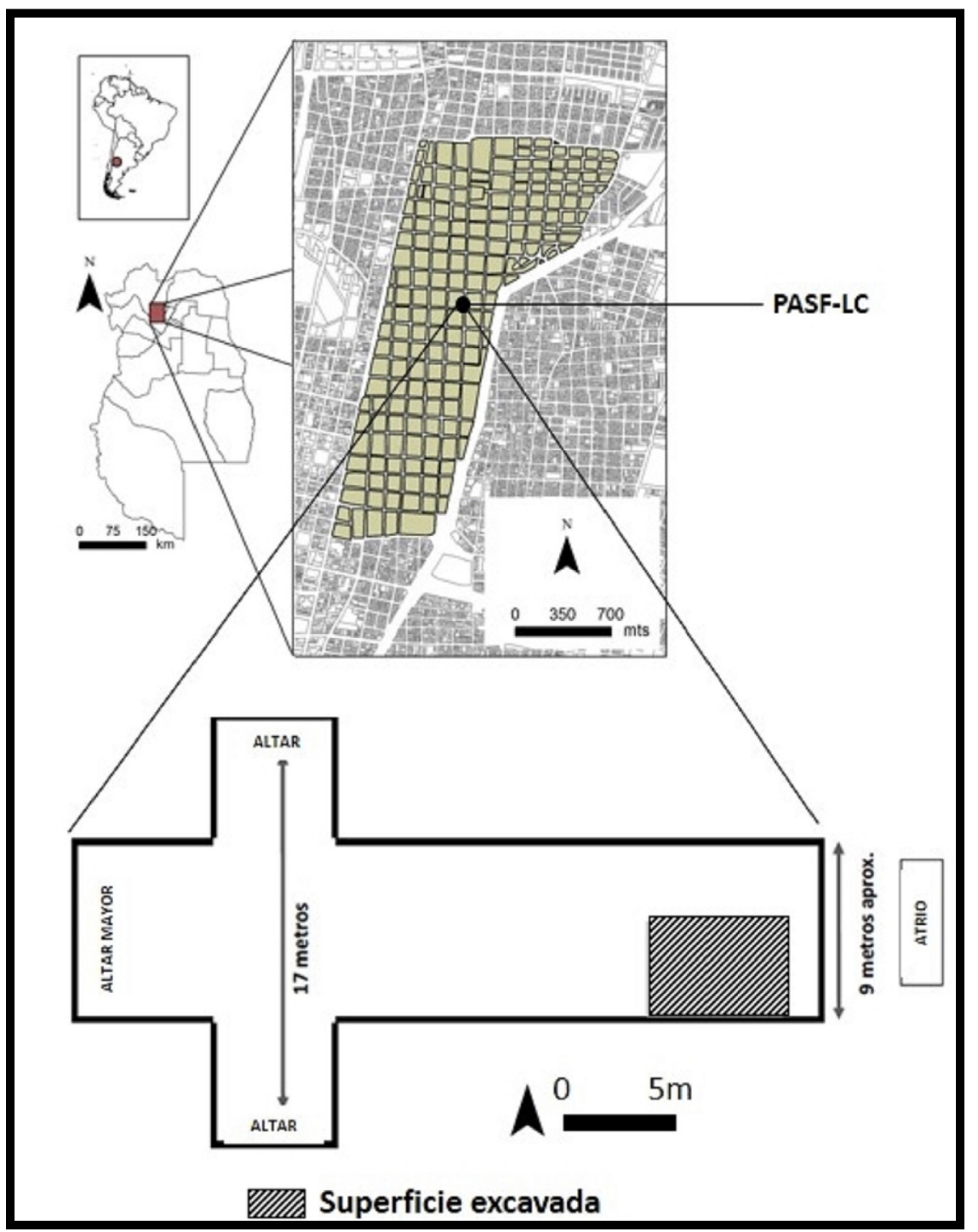

Figura 1. Ubicación del PA San Francisco-La Caridad dentro del Sitio Área Fundacional (cuadras coloreadas). Proyección hipotética del templo (línea continua) y área excavada (trama).

últimos conjuntos son resultado de la remoción por reutilización del templo como estructura funeraria. En el caso concreto del PALC-SF, los tipos de entierro permitirían incluso una hipotética adscripción socioeconómica. Los entierros primarios, individuos completos o semicompletos en posición anatómica corresponderían a las inhumaciones más tardías, es decir, al momento de administración del templo por la Hermandad de La Caridad. Los entierros secundarios, conjunto de restos óseos mezclados y desagregados, corresponderían principalmente a las inhumaciones más tempranas que fueron impacta- das y alteradas por nuevos entierros (Chiavazza y Zorrilla, 2008; Mansegosa et al., 2014) (Figura 2).

En la muestra bioarqueológica recuperada se reconstruyeron los perfiles de mortalidad (Giannotti y Mansegosa, 2011; Mansegosa et al., 2014; Mansegosa, 2015a), se analizó la distancia poblacional desde un punto de vista morfológico (Mansegosa, 2015b) y por último se evaluaron bioindicadores de dieta, salud y nutrición (Chiavazza, Mansegosa y Gil, 2015; Mansegosa, 2015a, 2016; Mansegosa y Chiavazza, 2010). Los indicadores de salud como 
las hipoplasias del esmalte dental, hiperostosis porótica y cribra orbitalia sugieren, teniendo en cuenta los perfiles de mortalidad, diferencias en la frecuencia y estado de las lesiones entre los individuos de entierros primarios y secundarios. Las mismas fueron interpretadas como una mayor resistencia y superación de estresores ambientales por parte de individuos de entierros secundarios, apoyando la hipótesis de procedencia social de inhumaciones en este templo (Mansegosa, 2015a; Giannotti, 2016b).
Se estudiaron 1161 dientes permanentes correspondientes a individuos adultos. Este total se divide en dos submuestras: 195 dientes correspondientes a individuos de entierros primarios, que se denominarán dientes articulados, y 966 dientes sueltos y mezclados asociados a entierros secundarios, que se denominarán dientes desarticulados (ver Tabla 1). El mal estado de conservación del tejido de los restos óseos de la muestra de entierros secundarios (Mansegosa, 2010) representa una limitación

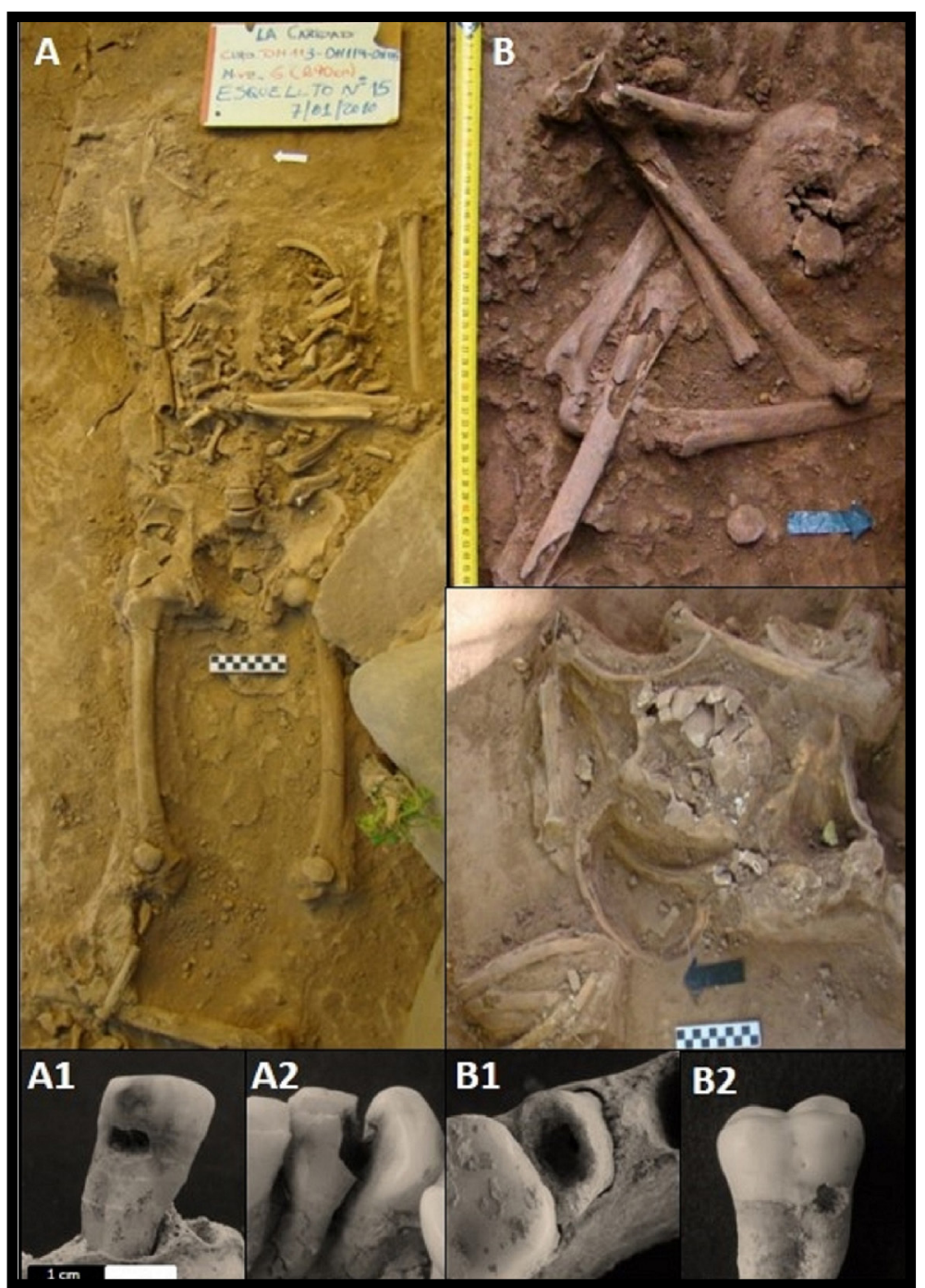

Figura 2. Entierro primario (A) y entierros secundarios (B). A1: Lesión cariosa interproximal en el primer premolar izquierdo inferior en un adulto mayor femenino (Individuo LC22). A2: Lesión cariosa interproximal del segundo incisivo y distal del canino derecho inferior en un adulto medio femenino (Individuo LC40). B1: Lesión cariosa de ubicación indeterminada con destrucción total de la corona en el segundo premolar izquierdo inferior del conjunto desarticulado. B2: Lesión cario-

sa buco/lingual en la corona del primer molar inferior derecho del conjunto desarticulado. 
metodológica en dos sentidos. En primer lugar, la imposibilidad de calcular la pérdida de dientes antemortem y enfermedades periodontales; y en segundo lugar, la dificultad para determinar el sexo.

El relevamiento de lesiones cariosas se realizó en todos los dientes (incisivos, caninos, premolares y molares) de ambas lateralidades, tanto superiores como inferiores de manera macroscópica con la ayuda de un explorador dental que permite examinar la presencia de cavitaciones de origen carioso. La lesión se registró como presente cuando la desmineralización formó una cavidad distintiva en el diente (Hillson, 2008). Se registró la ubicación de la lesión de acuerdo con el sistema modificado por Buikstra y Ubelaker (1994) para las lesiones en la corona y el de Hillson (2001) para aquellas ubicadas en la superficie de la raíz. La extensión de las lesiones se registró de acuerdo con los criterios de Hillson (2001). Cuando había más de una lesión por diente, se registró cada una por separado.

Los dientes fueron clasificados en dos categorías: dentición anterior (en adelante DA), que incluye incisivos y caninos; y dentición posterior (en adelante DP), que incluye premolares y molares. Los diferentes tipos de dentición tienen características morfológicas y funcionales distintas que implican una exposición diferencial a la caries (Hillson, 2008). Por esta razón, la prevalencia de dientes cariados se calculó para cada tipo de dentición; es decir, el número total de dientes cariados dividido en el número total de dientes anteriores y posteriores independientemente. Debe tenerse en cuenta que las tasas de caries están afectadas por la pérdida de dientes ante y postmortem y que existen modelos de corrección para aumentar la precisión (Hillson, 2001). En este trabajo no es posible aplicar estos métodos porque los alveolos se encuentran escasamente representados y no están asociados a los dientes, por lo tanto se hace una estimación general de la prevalencia de caries.

El sexo solo pudo ser determinado en entierros primarios. En los dientes sueltos y aislados no pudo ser determinado debido a la ausencia de estructuras diagnósticas asociadas. Por esta razón, no podemos realizar comparaciones de prevalencias de caries por sexo entre ambas submuestras. El sexo fue asignado a partir de variables de cráneo (proyección de la cres- ta nucal, tamańo del proceso mastoide, espesor del margen supraorbital y proyección de la prominencia mentonina) y de la pelvis (arco ventral, concavidad subpúbica, rama isquiopúbica, ángulo de la escotadura ciática mayor) siguiendo los métodos detallados en Buikstra y Ubelaker (1994).

La edad se estimó con distintas metodologías según se trate de entierros primarios o secundarios. En los individuos de entierros primarios, se estimó la edad al momento de la muerte siguiendo los métodos de Brooks y Suchey (1990), Todd (1921, citado en Buikstra y Ubelaker, 1994) e Isçan et al. (1984, citado en Bass, 1995). En los dientes desarticulados la edad se estimó a partir de una metodología desarrollada para poblaciones locales, en la cual se establecieron rangos cronológicos de 10 años de acuerdo al grado de desgaste de cada tipo de dentición anterior y posterior (Mansegosa y Giannotti, 2015). En esta submuestra, el NMI se estimó a partir de los dientes más representados según lateralidad (izquierda/derecha), ubicación (maxilar/mandibular) y rango etario estimado a partir del grado de desgaste del esmalte.

Los dientes de ambas submuestras se clasificaron en cuatro categorías de edad siguiendo a Buikstra y Ubelaker (1994): adulto joven (20-34 ańos), adulto medio (35-49 años), adulto mayor (mayor de 50 ańos) y en aquellos individuos en los que no se pudo estimar la edad se estableció como adulto indeterminado. La submuestra de entierros primarios comprende 11 individuos, $1(9,09 \%)$ es adulto joven, 4 $(36,36 \%)$ son adultos medios, $3(27,27 \%)$ adultos mayores y $3(27,27 \%)$ adultos de edad indeterminada. En esta submuestra $6(54,54 \%)$ son femeninos y 5 masculinos $(45,45 \%)$. En los entierros secundarios, sobre un NMI de 41 adultos, se identificaron $10(24,39 \%)$ adultos jóvenes, $23(56,1 \%)$ adultos medios y $8(19,51 \%)$ adultos mayores. El sexo no pudo determinarse en este conjunto. La cantidad de dientes correspondientes a cada categoría de edad de ambas submuestras se observa en la Tabla 1 .

Se analiza la prevalencia de lesiones cariosas por grupo de edad y por cronología comparando ambas submuestras. Para poder realizar comparaciones, los cálculos se efectuaron por diente y no por individuos, dada la naturaleza de la submuestra desagregada. 
Tabla 1. Composición de la muestra analizada. (DA) Dentición Anterior. (DP) Dentición posterior.

\begin{tabular}{|c|c|c|c|c|c|c|c|}
\hline \multirow{3}{*}{ Edad } & \multicolumn{7}{|c|}{ Dientes } \\
\hline & \multicolumn{3}{|c|}{ Entierros Primarios } & \multicolumn{3}{|c|}{ Entierros Secundarios } & \multirow{2}{*}{ Tota } \\
\hline & DA & DP & Subtotal & DA & DP & Subtotal & \\
\hline 20-34 años & 2 & 0 & 2 & 67 & 178 & 245 & 247 \\
\hline 35-49 años & 32 & 46 & 78 & 230 & 329 & 559 & 637 \\
\hline$\geq 50$ & 12 & 22 & 34 & 79 & 83 & 162 & 196 \\
\hline Adulto Indeterminado & 31 & 50 & 81 & - & - & - & 81 \\
\hline Total & 77 & 118 & 195 & 376 & 590 & 966 & 1161 \\
\hline
\end{tabular}

Por otra parte, la distribución de lesiones cariosas por sexo solo pudo ser evaluada en los entierros primarios. Para los cálculos de significancia estadística se utilizó el test $X 2$ y el test exacto de Fisher (Sampieri et al., 1991).

\section{Resultados}

En términos generales el 9,3\% de los dientes presentaban caries. Aquellos correspondientes a la DP $(11.4 \%)$ registran mayores tasas que los de la DA $(5,9 \%)$. Respecto de la edad, los individuos adul- tos mayores son los que presentan tasas más elevadas de lesiones (DA: 12,1\% y DP: 18\%), mientras que los adultos jóvenes y los adultos medio presentan prevalencias más bajas y muy similares entre sí (DA: $4,3 \%$ y $4,6 \%$ y DP: $9,6 \%$ y $10,7 \%$, respectivamente). En la muestra total las diferencias entre las tasas de caries según la edad resultaron significativas $(X 2=0.031 ; p<0.005)$, pero no dentro de cada tipo de dentición. En la Tabla 2 se observan los resultados de las prevalencias de caries para el total de la muestra según tipo de dentición y por grupo de edad.

Tabla 2. Tasa de caries en el total de la muestra por grupo etario y tipo de dentición. (DC) Dientes con caries. (TDO) Total de dientes observados. (\%DC) Tasas de dientes con caries.

\begin{tabular}{|l|l|l|l|l|l|l|}
\hline \multirow{2}{*}{ Dentición } & \multicolumn{1}{|c|}{$\begin{array}{c}\text { DC /TDO } \\
\text { \%DC }\end{array}$} & $\begin{array}{l}\text { Adulto } \\
\text { Joven }\end{array}$ & $\begin{array}{l}\text { Adulto } \\
\text { Medio }\end{array}$ & $\begin{array}{l}\text { Adulto } \\
\text { Mayor }\end{array}$ & Adulto Indeterminado & $\begin{array}{l}\text { Valor } \\
p\end{array}$ \\
\hline \multirow{2}{*}{ Anterior } & $27 / 453$ & $3 / 69$ & $12 / 262$ & $11 / 91$ & $1 / 31$ & 0.054 \\
\cline { 2 - 7 } & $5.9 \%$ & $4.3 \%$ & $4.6 \%$ & $12.1 \%$ & $3.2 \%$ & 0.148 \\
\hline \multirow{2}{*}{ Posterior } & $81 / 708$ & $17 / 178$ & $40 / 375$ & $19 / 105$ & $5 / 50$ & $10 \%$ \\
\cline { 2 - 7 } & $11.4 \%$ & $9.6 \%$ & $10.7 \%$ & $18 \%$ & $6 / 81$ & 0.031 \\
\hline
\end{tabular}


La tasa de caries según sexo solo pudo calcularse en la muestra de entierros primarios. El 6,5\% (8/124) de los dientes de los individuos femeninos presentaron lesiones cariosas, mientras que en los masculinos este porcentaje fue algo menor, 2,8\% (2/71). Estas diferencias no son estadísticamente significativas (Test exacto de Fisher $=0,225 ; p<0.005$ ).

En la Tabla 3 se muestra el total de lesiones por submuestra y por tipo de dentición. Dentro de cada submuestra la tasa total de caries registrada resultó similar pero levemente superior $(9,7 \%)$ en los dientes del conjunto articulado en relación a los desagre- gados $(9,2 \%)$. Esta diferencia no es significativa desde el punto de vista estadístico $(X 2=0.996 ; p<0.05)$. Cuando comparamos las submuestras teniendo en cuenta el tipo de dentición, estas diferencias son más marcadas. A este respecto, dentro de la DA los dientes de la submuestra articulados (13\%) presentan mayor tasa de caries que los de la submuestra desarticulados $(4,5 \%)$, diferencias que resultan estadísticamente significativas $(X 2=0.006 ; p<0.05)$. En la DP la tendencia es inversa, los desarticulados $(12,2 \%)$ presentan más caries que los articulados (7,6\%); sin embargo, estas diferencias no resultan estadísticamente significativas $(X 2=0.104 ; p<0.05)$.

Tabla 3. Comparación de la tasa de caries según submuestra. (DC) Dientes con caries.

(TDO) Total de dientes observados. (\%DC) Tasas de dientes con caries.

\begin{tabular}{|l|l|l|l|l|}
\hline \multirow{2}{*}{ Dentición } & $\begin{array}{l}\text { Articulados } \\
\text { DC } / \text { TDO } \\
\text { \%DC }\end{array}$ & $\begin{array}{l}\text { Desarticulados } \\
\text { DC } / \text { TDO } \\
\text { \%DC }\end{array}$ & $\begin{array}{l}\text { Total } \\
\text { DC /TDO } \\
\% \text { DC }\end{array}$ & \multirow{2}{*}{ Valor $p$} \\
\hline \multirow{2}{*}{ Anterior } & $10 / 77$ & $17 / 376$ & $27 / 453$ & \multirow{2}{*}{0.006} \\
\cline { 2 - 4 } & $13 \%$ & $4.5 \%$ & $5.9 \%$ & \multirow{2}{*}{0.104} \\
\hline \multirow{2}{*}{ Posterior } & $9 / 118$ & $72 / 590$ & $81 / 708$ & \multirow{2}{*}{0.996} \\
\cline { 2 - 4 } & $7.6 \%$ & $12.2 \%$ & $11.4 \%$ & \\
\hline \multirow{2}{*}{ Total } & $19 / 195$ & $89 / 966$ & $108 / 1161$ & \\
\cline { 2 - 4 } & $9.7 \%$ & $9.2 \%$ & $9.3 \%$ & \\
\hline
\end{tabular}

Tabla 4. Caries según submuestra, tipo de dentición y grupo etario. (DA) Dentición Anterior. (DP) Dentición Posterior. (DC) Dientes con lesiones cariosas. (TDO) Total de dientes observados. (\%DC) Tasas de dientes con lesiones cariosas.

\begin{tabular}{|c|c|c|c|c|c|c|c|}
\hline \multicolumn{2}{|l|}{ Submuestra } & $\begin{array}{l}\text { Adulto } \\
\text { Joven } \\
\text { DC /TDO } \\
\text { \%DC }\end{array}$ & $\begin{array}{l}\text { Adulto } \\
\text { Medio } \\
\text { DC /TDO } \\
\text { \%DC }\end{array}$ & $\begin{array}{l}\text { Adulto } \\
\text { Mayor } \\
\text { DC /TDO } \\
\text { \%DC }\end{array}$ & $\begin{array}{l}\text { Adulto Indetermi- } \\
\text { nado } \\
\text { DC /TDO } \\
\% \text { DC }\end{array}$ & $\begin{array}{l}\text { Total } \\
\text { DC / } \\
\text { TDO } \\
\text { \%DC }\end{array}$ & $\begin{array}{l}\text { Valor } \\
p\end{array}$ \\
\hline \multirow[t]{4}{*}{ Articulados } & \multirow[t]{2}{*}{ DA } & $0 / 2$ & $8 / 32$ & $1 / 12$ & $1 / 31$ & $10 / 77$ & \multirow[t]{2}{*}{0.83} \\
\hline & & $0 \%$ & $25 \%$ & $8.3 \%$ & $3.2 \%$ & $12.9 \%$ & \\
\hline & \multirow[t]{2}{*}{ DP } & - & $2 / 46$ & $2 / 22$ & $5 / 50$ & $9 / 118$ & \multirow[t]{2}{*}{0.592} \\
\hline & & - & $4.3 \%$ & $9 \%$ & $10 \%$ & $7.6 \%$ & \\
\hline \multirow[t]{4}{*}{ Desarticulados } & \multirow[t]{2}{*}{ DA } & $3 / 67$ & $4 / 230$ & $10 / 79$ & - & $17 / 376$ & \multirow[t]{2}{*}{0.001} \\
\hline & & $4.5 \%$ & $1.7 \%$ & $12.7 \%$ & - & $4.5 \%$ & \\
\hline & \multirow[t]{2}{*}{ DP } & $17 / 178$ & $38 / 329$ & $17 / 83$ & - & $72 / 590$ & \multirow[t]{2}{*}{0.065} \\
\hline & & $9.6 \%$ & $11.6 \%$ & $20.5 \%$ & - & $12.2 \%$ & \\
\hline
\end{tabular}


En la Tabla 4 se detallan las prevalencias y tasas de caries en cada submuestra. En la submuestra de dientes correspondientes a individuos articulados (entierros primarios), los que presentan mayores tasas de caries en la DA son los adultos medios (25\%), mientras que en la DP son los adultos mayores $(8,3 \%)$. En la submuestra de dientes desarticulados (entierros secundarios), los adultos mayores registran las mayores tasas de caries tanto en la DA (12.7\%) como en la DP (20.5\%). Estas diferencias solo fueron estadísticamente significativas en la DA del conjunto desarticulado (Test exacto de Fisher= $0.001 ; p<0.05)$.

Por otra parte, en la Figura 3 se comparan las tasas entre cada submuestra para la DA y la DP.
En cuanto a la ubicación de las lesiones, podemos observar algunas diferencias (Figura 4). En los dientes de la submuestra articulados solo está afectada la corona $(100 \%)$, con ausencia total de caries en la raíz y en la región cervical. En la DA las lesiones están localizadas principalmente en la superficie interproximal $(60 \%)$. También hay lesiones grandes que afectan la totalidad de la corona $(30 \%)$ y menos en la superficie oclusal (10\%). Esta distribución cambia notablemente en la DP, donde la mayor concentración de lesiones se da en la superficie oclusal (60\%). Las lesiones grandes (de ubicación indeterminada) en la DP que afectan toda la corona tienen igual tasa que en la DA (30\%), mientras que las interproximales solo representan el 10\%. En los dientes de la submuestra desarticulados, hay una distribución

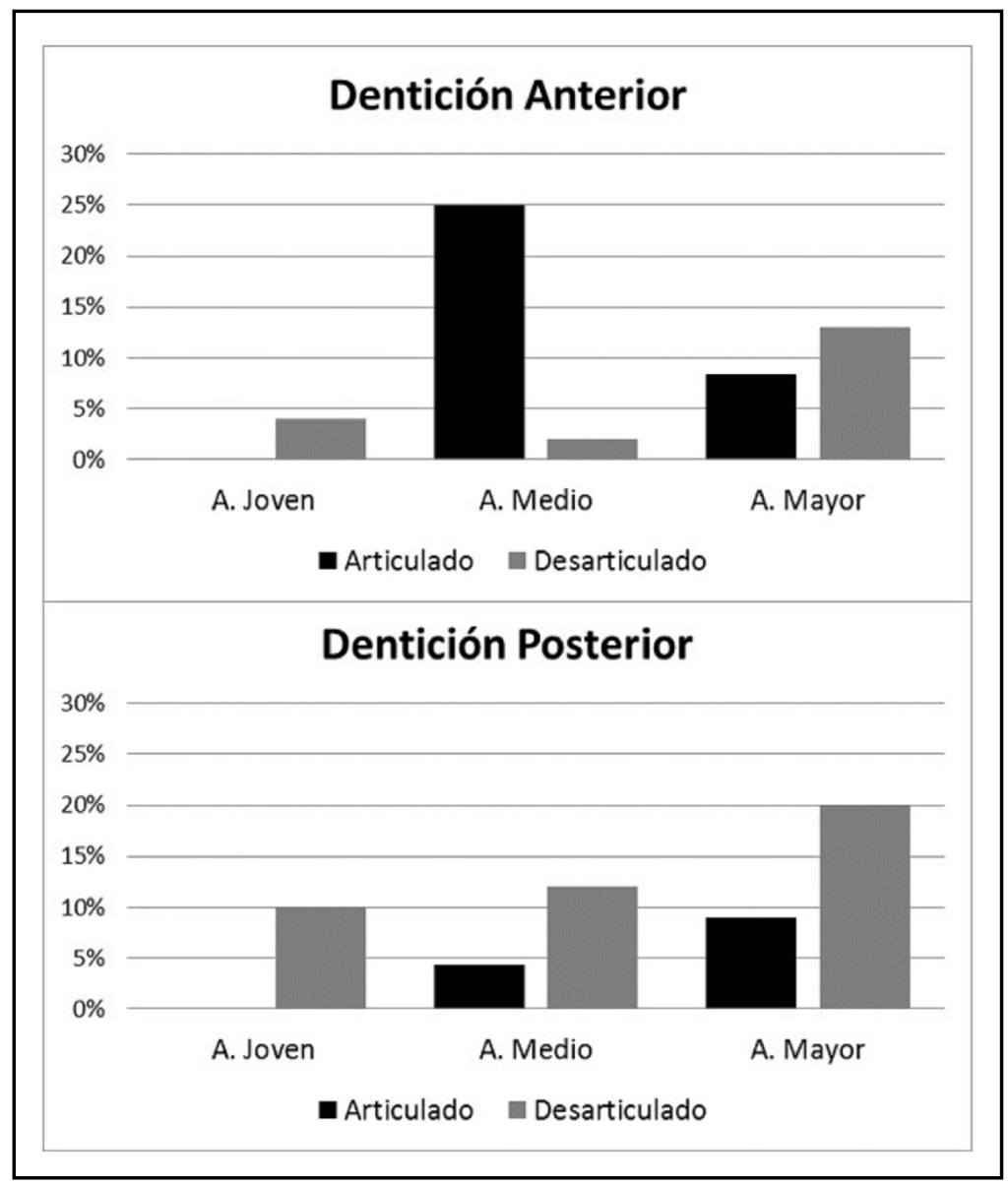

Figura 3. Porcentajes de lesiones cariosas en la Dentición Anterior (arriba) y Dentición Posterior (abajo) según submuestra y categoría de edad. 


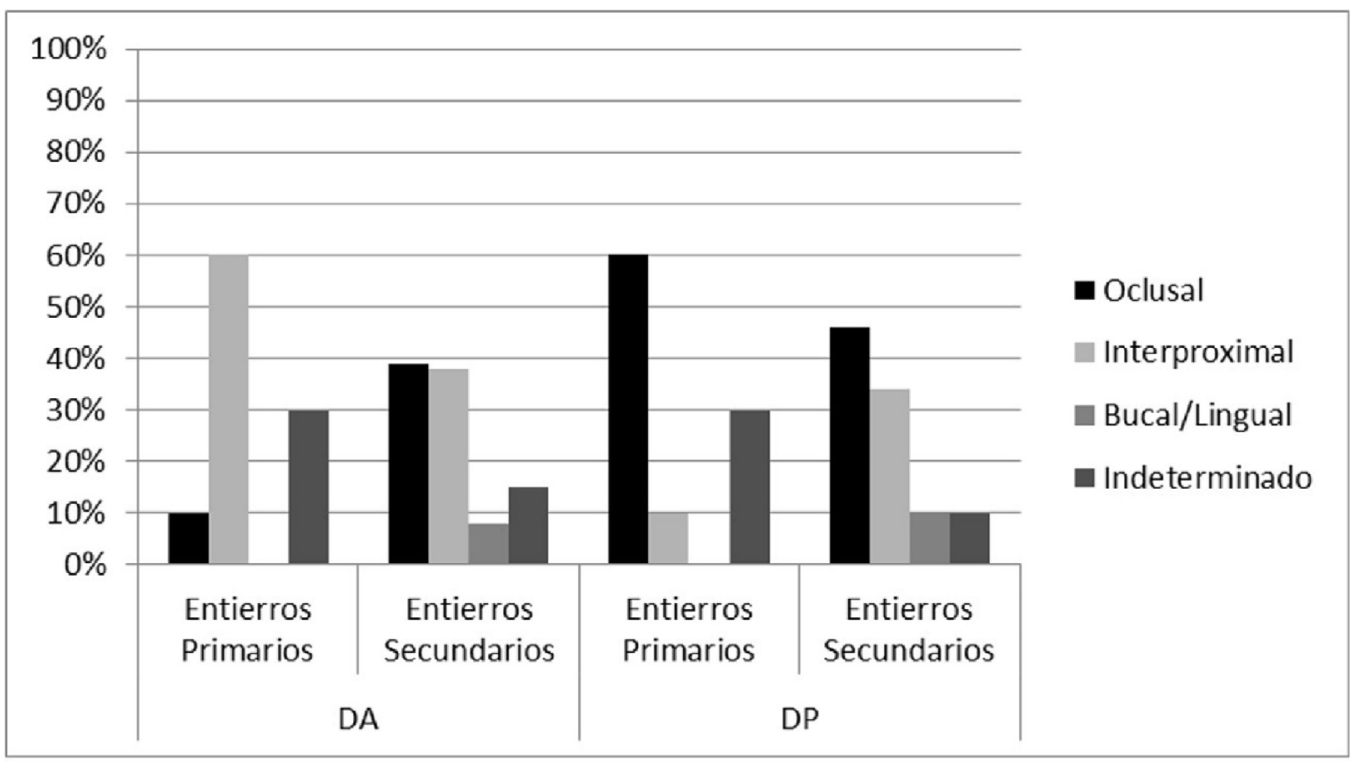

Figura 4. Distribución de las lesiones cariosas por submuestra según su localización en la Dentición Anterior (DA) y Dentición Posterior (DP).

más heterogénea que afecta a la corona (82\%), la región cervical $(16 \%)$ y la raíz $(2 \%)$. En la DA la superficie interproximal y la oclusal están igualmente afectadas (38\%); las lesiones grandes también están presentes $(16 \%)$ y una tasa menor en las zonas bucal/lingual (8\%). En la DP, la superficie oclusal presenta una tasa mayor (46\%), seguida de la zona interproximal (34\%), y la zona bucal/lingual e indeterminada con una igual tasa de afectación (10\%).

\section{Discusión}

La muestra aquí trabajada presenta una tasa de caries de 9,3\%, valor muy cercano al límite superior propuesto por Turner (1979) para sociedades con dietas mixtas o dentro del rango para sociedades agrícolas, lo que sugiere, como era esperable, una dieta basada en gran medida en plantas ricas en carbohidratos. La caries dental se asocia estrechamente con la cantidad de hidratos de carbono, azúcar y alimentos blandos que se consumen en la dieta (Turner, 1979; Larsen et al., 1991; Lukacs, 1992; Larsen, 2015). Estos valores son similares a los obtenidos en muestras bioarqueológicas de otros puntos arqueológicos del Área Fundacional, como Ruinas de San Francisco (Mansegosa, 2015a). Los estudios previos en entierros primarios del PALC-SF establecieron que el $45,5 \%$ de los individuos presentaban al menos una lesión de caries (Mansegosa, 2015a, 2015b). Cuando comparamos estas tasas con las registradas en otras poblaciones, observamos una gran variabilidad. En poblaciones prehispánicas del norte de la región de Cuyo con economías agrícolas, Bernal et al. (2007) registraron un porcentaje de caries muy similar (9,5\% en los adultos jóvenes y de $10,53 \%$ en adultos de mediana edad). Por otra parte, en una muestra con cronologías de 1000 y de 200 años antes del presente de 40 individuos adultos de diferentes puntos del centro y norte de Mendoza, se observó que el $45,5 \%$ de individuos tenían caries con un porcentaje de dientes afectados de $4,5 \%$, lo cual fue interpretado como una baja ingesta de carbohidratos (Novellino et al., 2004). Para períodos cronológicos similares al de la muestra, los resultados han sido muy variados. En una muestra de 9 individuos adultos del siglo XIX recuperados en el cementerio de la Misión Salesiana Nuestra Señora de Candelaria (Tierra del Fuego, Argentina) el $67 \%$ de los individuos que presentaron caries fue relacionado por los autores con un consumo de alimentos con mayor procesamiento (García Laborde 
et al., 2010). En Santiago de Chile, de una muestra de 108 individuos adultos del cementerio colonial de La Pampilla (principios siglo XIX), correspondiente al camposanto del antiguo Hospital Real San Juan de Dios, el 20\% presentaron lesiones cariosas, lo cual se vinculó con alimentos muy procesados (blandos), con un contenido moderado de carbohidratos (Henríquez Urzúa y Prado Berlien, 2010). En otro cementerio histórico de Chile, de la parroquia La Purísima Concepción de Colina (fines siglo XVI - mediados siglo XIX), el 33,3\% de los individuos registraban caries (Rodríguez et al. 2004).

En cuanto a los resultados obtenidos en este trabajo, observamos prevalencias diferentes entre grupos de edad y sexo. Su distribución por grupos etarios indica como tendencia general un aumento progresivo de las caries, con una mayor prevalencia en adultos mayores, seguidos de adultos medios y jóvenes; esto se explica a partir de que la caries es un proceso crónico progresivo con la edad (Hillson, 2008; Wasterlain et al., 2009). Las mujeres registran mayores tasas de caries en relación a los hombres, aunque esta diferencia no es significativa por lo que esto supone un acceso similar a los alimentos cariogénicos entre los sexos. Sin embargo, esta mayor propensión en mujeres también se ha registrado en otras poblaciones, lo cual puede indicar un mayor consumo o frecuencia de alimentos cariogénicos, así como también a la incidencia de procesos fisiológicos como el embarazo y la lactancia que favorecen el desarrollo de esta patología (Lukacs y Largaespada, 2006; Wasterlain et al., 2009).

Los valores similares de caries en las dos submuestras (dientes de entierros secundarios y de entierros primarios) sugieren una cantidad similar de carbohidratos consumidos en las dietas de los diferentes sectores socioeconómicos. Sin embargo, la distribución de las lesiones cariosas en la dentición (DA/ DP) y su ubicación puede indicar diferencias en los estilos de vida de los inhumados.

En este sentido, en la submuestra de dientes desarticulados la mayor concentración de lesiones se da en la DP y afectan tanto la corona como la raíz y la región cervical. En contraste, la submuestra de dientes articulados presenta mayor concentración en la DA y afectan únicamente la corona. Tales diferencias pueden ser atribuidas a que los individuos de la submuestra desarticulados (mayores recursos socioeconómicos) tuvieron un mayor consumo de alimentos ricos en azúcar y carbohidratos fermentables, con una textura más pegajosa/pastosa que facilita la depositación del mismo en distintas superficies de la DP generando caries, como por ejemplo dulces o harinas más refinadas (Cano Rossini, 1996; Giamportone, 1998). Las caries extraoclusales, es decir, ubicadas en superficies lisas o en la región cervical, están asociadas a alimentos ricos en sacarosa (p.e. azúcar) o maltosa y maltodextrinas contenidas en almidones simples (p.e. trigo) (Lingström et al., 2000; Ribeiro et al., 2005). Por otra parte, la mayor prevalencia de caries en DA en detrimento de la DP de la submuestra articulados (menores recursos socioeconómicos) no solo da cuenta de una dieta con alimentos con textura menos pegajosa/pastosa, sino que probablemente estén actuando otros factores. Por un lado, las caries ubicadas en la DA pueden estar asociadas con el uso paramasticatorio de los dientes (p.e. trabajo del cuero, textiles, cestería) (Albashaireh y Al-Shorman, 2010). En este sentido la elevada tasa de caries en el grupo de los adultos medios puede vincularse con la participación en las actividades productivas y la utilización de los dientes como herramienta, principalmente entre las personas de menores recursos. Por otro lado, la mala calidad de la harina (caracterizada por un grano de mediano a grande) y la posibilidad de ingreso de partículas abrasivas mediante el procesamiento (con la piedra solera de los molinos harineros de trigo y cebada y la alternancia de molienda de granos con las de minerales) (Cano Rossini, 1996; Figueroa, 2006) pudieron haber favorecido el desgaste dental generando las condiciones para el desarrollo de lesiones cariosas. Este fenómeno ha sido registrado en otras poblaciones donde procesan los alimentos con piedras de moler (Eshed et al., 2006). El consumo de este tipo de harina pudo ser generalizado entre sectores de menores recursos frente a grupos sociales más ricos, quienes tenían acceso a harinas de calidad más refinada. Por esta razón, consideramos necesario profundizar en análisis de patrones de desgaste dental específicos a partir de observaciones macroscópicas y microscópicas para seguir avanzando en esta línea interpretativa. 
También se observaron diferencias en la localización de las lesiones. En la submuestra de dientes articulados, las lesiones de la DA se encontraban principalmente en las superficies interproximales, mientras que en la DP se ubicaban en la superficie oclusal, y en ambas denticiones las lesiones grandes (lugar de origen indeterminado) estaban muy representadas. Respecto a la submuestra de dientes desarticulados, la localización de las lesiones resultó más variable, afectando principalmente las superficies interproximales, oclusales, cervicales e indeterminadas, tanto en la DA como en la DP. Pensamos que las caries ubicadas en zona de contacto entre dientes pueden deberse a depósitos de alimentos más pegajosos/pastosos. En este sentido, las formas de procesamiento a partir de técnicas variables como el asado o el hervido pueden haber producido alimentos con distinta textura (duros/blandos) que podrían explicar estas diferencias en la localización. Los estudios de desgaste realizados en esta muestra registran grados de desgaste variables, pero concentrados del 2 al 5 en dientes desagregados (Giannotti, 2016b), y en articulados de entierros primarios se centran principalmente entre los grados 4 al 6 (Mansegosa, 2015a). Esta información apoya las interpretaciones acerca de la posibilidad del consumo de alimentos con distinta dureza por parte de los diferentes sectores socioeconómicos. Otro aspecto que pudo haber contribuido a la localización de las caries en zonas interproximales puede ser la pérdida de dientes antemortem. Ya que se tiende a realizar un movimiento axial durante la masticación para compensar la pérdida de superficie masticatoria, las regiones interproximales se convierten en lugares propensos para el estancamiento de alimento y por lo tanto más vulnerables a la caries dental. Esto está apoyado por la alta pérdida de dientes antemortem hallados en entierros primarios $(n=47 / 140 ; 35 \%)$ (Mansegosa, 2016).

El consumo de bebidas alcohólicas (vino, chicha, licores) también pudo haber contribuido al desarrollo de caries, ya que tienen bajos niveles de $\mathrm{pH}$ que generan una erosión en el esmalte (cupping) y expone la dentina, promoviendo el desarrollo de la caries (Albashaireh y Al-Shorman, 2010). El hecho de que Mendoza sea productora de estas bebidas favoreció el consumo interno generalizado, aunque el tipo y calidad de la bebida podría estar determinada por el grupo social que lo consumía: mientras que grupos sociales más "acomodados" consumían vino (en sus diversas variedades), los grupos de menores recursos bebían la chicha y los licores, más baratos y abundantes, llegando incluso a crearse una afición permanente de su consumo por parte de estos sectores (Cano Rossini, 1996). Esta situación es reflejada por otros autores, incluso durante todo el siglo XIX (Lemos, 1897; Bialet Masse, 1968 [1904]).

Al comparar las tasas de caries por edad entre cada submuestra, se detecta que en la submuestra de dientes desagregados (mayores recursos socioeconómicos) las lesiones de caries aparecen más tempranamente (adultos jóvenes 20-34 años) y aumenta progresivamente con la edad. Esto sugiere un consumo más temprano y constante de carbohidratos que reforzaría lo mencionado en los párrafos anteriores. En este sentido, remarcamos la necesidad de continuar profundizando en el estudio de estas tendencias, ya que el tamańo y las características etarias de las submuestras son diferentes y podrían estar sesgando los resultados, problemas que resultan comunes en estudios comparativos. Por esta razón, los resultados obtenidos son considerados como una tendencia que deberá constatarse mediante estudios futuros.

A pesar de la ingesta similar de carbohidratos en ambas submuestras (sugeridas por las tasas de caries), la documentación histórica sostiene que solo los sectores más acomodados tenían acceso a alimentos de alto valor cariogénico tales como el azúcar y harinas refinadas. Los sectores más pobres, en cambio, pueden haber tenido acceso habitual a carbohidratos (harinas de trigo y cebada), tal vez en formas menos refinadas (procesadas). Esto, sumado al tipo de cocción, lo convierte en un alimento menos pegajoso y más abrasivo que se reflejaba en un menor porcentaje de caries en la DP.

La higiene oral y prácticas odontológicas asociadas representan un conjunto de acciones que tuvieron alguna incidencia en la frecuencia y distribución de las lesiones cariosas, ya sea como inhibidor o fomentador de dichas lesiones. En cuanto a la higiene oral, la tasa de caries en ambas submuestras no pareciera sostener una conducta claramente distinguible en la limpieza oral (p.e. cepillado). La aparente falta de higiene oral en ambos grupos socioeconómicos podría estar corroborada por las menciones indirectas 
presentes en la historiografía local. Sin embargo, no estamos en condiciones de afirmar, a partir de estos resultados, la existencia de una pobre o nula práctica de higiene oral, ya que deberíamos considerar otras variables analíticas (p.e. comparar tamaño y localización de tártaro dental). Al mismo tiempo, se hace necesario profundizar análisis específicos con el objetivo de detectar evidencia de acciones odontológicas tales como extracciones o drenados.

Otro de los factores que puede haber incidido en el desarrollo de caries son los niveles de flúor en el agua consumida, ya que tiene un efecto preventivo en el desarrollo de las caries. La presencia de iones de fluoruro en la red cristalina de hidroxiapatita del esmalte tiene un importante efecto inhibidor sobre la caries, al incrementar la resistencia del tejido dental (Hartles y Leach 1975; Hillson 2008). Por ejemplo, un estudio realizado en México a partir de poblaciones modernas que consumían 1,7 a 2,5 $\mathrm{mg} / \mathrm{l}$ de fluoruro en agua, presentaban la mitad de caries que aquellas que vivían en áreas con 0,6 a 0,7 mg/l (Volker y Russel, 1973, citado en Vega Lizama y Cucina, 2001). La concentración de flúor promedio registrado en cursos naturales de agua para la provincia de Mendoza presentan niveles medios de concentración, con valores que oscilan entre 0,3 a $1,7 \mathrm{mg} / \mathrm{l}$ (Martínez Prieto, 1988, citado en Bavera, 2006). El valor inferior de este rango se encuentra algo más bajo que el recomendado para el consumo de los habitantes del centro oeste argentino $(0,7$ $\mathrm{mg} / \mathrm{l})$, aunque el valor superior del mismo excede el límite recomendado (1,0 mg/l) (Código Alimentario Argentino, Ley 18.284, su Reglamento y modificaciones). Dado que estos valores de flúor no son muy elevados, podrían haber mantenido o disminuido la resistencia del tejido dental para el desarrollo de caries, pero no aumentado su resistencia (Hartles y Leach 1975; Hillson 2008). Esta información debe ser discutida en trabajos futuros teniendo en cuenta estudios de mineralización del esmalte dental sobre las muestras bioarqueológicas.

La genética es un factor que incide en la susceptibilidad individual a la caries. Estudios experimentales han logrado demostrar dicha incidencia por medio de los genes implicados en el desarrollo del esmalte, la función salival y la respuesta inmune (Vieira, 2012). La diversidad de poblaciones que habitaron en la ciudad colonial de Mendoza ha sido registrada por la documentación histórica (p.e. Prieto, 2000 [1983]) y detectada en las muestras bioarqueológicas del Sitio Área Fundacional (Mansegosa, 2015a). En el caso del PASF-LC, los resultados de un estudio de distancia poblacional en individuos articulados demostraron una composición heterogénea (poblaciones europeas, africanas y fundamentalmente nativas), pero con un elevado flujo génico entre dichos grupos y/o ascendencias genéticas comunes, lo cual fue interpretado como resultado del proceso de mestizaje experimentado hacia el siglo XVIII y principios del XIX (Mansegosa, 2015a). Si bien no disponemos de información directa sobre la composición genética de las primeras inhumaciones correspondientes a sectores de mayores recursos (restos óseos de entierros secundarios) (Giannotti, 2016b), se esperaría un patrón similar al registrado en otros templos coloniales del Área Fundacional, como el caso de las Ruinas de San Francisco, donde los individuos del interior presentaban una menor heterogeneidad y una adscripción a poblaciones fundamentalmente europeas (Mansegosa, 2015a). En consecuencia, la diversa gradiente genética existente en ambas submuestras de dientes analizados en este trabajo requiere evaluar la caries dental con recaudo y ofrece una línea de análisis que necesita ser profundizada en futuros estudios de salud oral y dieta.

\section{Conclusiones}

Los resultados del estudio de las tasas de caries obtenidos en este trabajo sugieren una moderada incidencia en el consumo de carbohidratos en la dieta de las poblaciones del norte de Mendoza durante el siglo XVIII hasta principios del siglo XIX. Por otro lado, la distribución de lesiones cariosas por tipo de dentición y ubicación probablemente se relacionan más con diferencias en el tipo, calidad y procesamiento de los alimentos. De acuerdo con los resultados y en relación a la estructura social de la muestra según su procedencia espacial, sugerimos que las personas de mayores recursos consumieron alimentos más refinados (ricos en carbohidratos y azucares) y de textura más pegajosa/pastosa desde edades más tempranas. Estos alimentos podrían relacionarse, según el registro histórico, con el azúcar, harinas de trigo, frutas y verduras, sumado a diversos productos más procesados derivados de éstos 
(p.e. pan, tabletas de fruta, mazamorra). Los dientes de las personas de menores recursos presentan una mayor cantidad de lesiones cariosas en la DA, en las superficies interproximales y lesiones grandes que afectan toda la corona, lo cual se relaciona con la posibilidad del uso paramasticatorio de la dentición y con un consumo de alimentos menos procesados (de mayor dureza) y más abrasivos. Si bien el análisis de una única variable no permite profundizar sobre el acceso diferencial de cuidados y tratamientos terapéuticos vinculados a la higiene oral de la muestra, las tasas de caries en ambas submuestras sugieren una higiene similar posiblemente a causa de la escasez -o ausencia- de determinados hábitos como el cepillado de los dientes. Sin embargo, esta hipótesis necesita ser contrastada con mayor información histórica y análisis bioarqueológicos específicos.

Se abren nuevos interrogantes que requieren ser abordados con análisis específicos tales como el de microdesgaste dental (para comparar la dureza de los alimentos consumidos entre los diferentes sectores socioeconómicos), detectar evidencias de prácticas odontológicas en el tejido óseo asociado a los dientes por medio de imágenes tomográficas e incrementar el análisis isotópico. Estos datos contribuirán a una mejor comprensión sobre el origen de la caries dental de las poblaciones históricas de Mendoza.

Más allá de las nuevas líneas de análisis que es necesario continuar, los resultados obtenidos en relación a la frecuencia y distribución de lesiones cariosas (por tipo de dentición, grupo etario y submuestra) refuerzan la hipótesis (sostenida por secuencias estratigráficas, disposición espacial de los entierros y resultados de análisis bioarqueológicos) que adscribe a los entierros secundarios y primarios del PALCSF con individuos de procedencia socioeconómica diferente $y$, consecuentemente, con consumos distintos. Por lo tanto, consideramos que este trabajo aporta más datos que permitirán discutir en las próximas investigaciones el impacto de las condiciones materiales de vida en la salud de las poblaciones coloniales mendocinas.

\section{Agradecimientos}

Al equipo del Centro de Investigaciones Ruinas de San Francisco, a la Municipalidad de la Ciudad de Mendoza, a la SECTyP UNCuyo; Facultad de Filosofía y Letras; AGENCIA y CONICET. También queremos agradecerle especialmente a la Dra. Lumila Menéndez por la lectura crítica de este manuscrito y las sugerencias que nos brindó, las cuales contribuyeron a enriquecer este trabajo. $\mathrm{Y}$ a los revisores por sus valiosos aportes.

\section{Referencias citadas}

Albashaireh, Z. S. M. y Al-Shorman, A. A. (2010). The frequency and distribution of dental caries and tooth wear in a Byzantine population of Sa'ad, Jordan. International Journal of Osteoarchaeology, 20(2), 205-213.

Araujo, E. (2015). Prácticas alimentarias en el periodo prehispánico tardío y colonial temprano en el Valle de Huentota (siglos XIV-XVI). En Libro de Resúmenes del VI Congreso Nacional de Arqueologia Histórica, p. 96. Facultad Filosofía y Letras de Universidad Nacional de Cuyo.

Ariès, P. (2000). Historia de la muerte en Occidente. Desde la Edad Media hasta nuestro dias. Barcelona: Editorial Acantilado.

Bass, W. (1995). Human Osteology: A Laboratory and Field Manual. Columbia: Missouri Archaeological Society.

Bavera, G. (2006). Flúor (f) y dentición. En Bavera G. (Ed.). Suplementación mineral y con NNP del bovino a pastoreo (pp. 91-97). Río Cuarto.

Bernal, V., Novellino, P., Gonzalez, P. y Perez, S. I. (2007). Role of Wild Plant Foods Among Late Holocene Hunter-Gatherers From Central and North Patagonia (South America): An Approach From Dental Evidence. American Journal of Physical Anthropology, 133,1047-1059.

Bialet Massé, J. M. (1968 [1904]). El estado de las clases obreras argentinas a comienzos del siglo. Universidad Nacional de Córdoba, Córdoba.

Brooks, S., y Suchey, J. (1990). Skeletal age determination based on the os pubis: a comparison of the Acsádi-Nemeskéri and Suchey-Brooks methods. Human Evolution, 5(3), 227-238. 
Buikstra, J. E. y Ubelaker, D. H. (1994). Standards for Data Collection from Human Skeletal Remains. Arkansas Archaeological Survey Research Series No 44. Arkansas.

Calderón, J. L. M. (1967). Mendoza hace cien años. Historia de la provincia durante la presidencia de Mitre. Buenos Aires: Ediciones Teoría.

Camino, U. (2013). San José de Flores de pueblo de campaña a barrio de una megaciudad. Cuadernos del Instituto Nacional de Antropología y Pensamiento Latinoamericano, Series Especiales, 1(3), 39-50.

Cano Rossini, L. (1996). La mujer mendocina de 1800. Una Revolución cultural en marcha. Mendoza: Ediciones Culturales de Mendoza.

Chiavazza, H. (2005). Los templos coloniales como estructuras funerarias. Arqueología en la iglesia jesuita de Mendoza. Londres: British Archaeological Reports. International Series 1388 .

Chiavazza, H. (2008). Bases teóricas para el análisis arqueológico de la espacialidad religiosa y los procesos de transformación cultural en la ciudad de Mendoza durante la colonia. Revista de Arqueología Americana, 25, 225-244.

Chiavazza, H. (2013). No tan simples: pesca y horticultura entre grupos originarios del Norte de Mendoza. Comechingonia virtual, 1, 27-45.

Chiavazza, H., y Maferra, L. (2007). Estado de las investigaciones arqueobotánicas en Mendoza y sus implicancias en la arqueología histórica. Revista de arqueología histórica Argentina y Latinoamericana, 1, 127-152.

Chiavazza, H., Manegosa, D., Gámez Mendoza, A. y Giannotti, P. S. 2015. Funebria católica y estimaciones del sexo y de la edad en entierros de una ciudad americana colonial (Mendoza, Argentina, siglos XVII-XIX). Revista de Arqueología Histórica Argentina y Latinoamericana, 9(1), 35-70. Buenos Aires.

Chiavazza, H., Manegosa, D. y Gil, A. (2015). Human diet and residential mobility in the Central Western Argentina colony: stable isotopes $(13 \mathrm{C}, 15 \mathrm{~N}, 18 \mathrm{O})$ trends in archaeological bone samples. International Journal of Historical Archaeology, 19(2), 289-308.
Chiavazza, H., y Zorrilla, V. (2008) Ms. Informe de las excavaciones en la Escuela Federico antigua Iglesia de la Caridad y primer templo franciscano. Centro de Investigaciones Ruinas de San Francisco. Manuscrito inédito.

Código Alimentario Argentino (2007). Capítulo XII: Bebidas Hídricas, Agua y Agua Gasificadas. Art. 982. Recuperado de http://www.anmat.gov.ar/alimentos/codigoa/ Capitulo_XII.pdf.

Comadrán Ruiz, J. F. (1968). Historia politica, económica, social y cultural de la provincia de Cuyo. Buenos Aires: Centro Editor de América Latina.

Coni, E. (1897). Saneamiento de la provincia de Mendoza. Buenos Aires: Imprenta P. E. Coni.

Coria, L. A. (1988). Evolución económica de Mendoza en la época colonial. Mendoza: Ediciones Culturales de Mendoza.

Cueto, A. (1991). La ciudad de Mendoza: su historia a través de cinco temas. Buenos Aires: Fundación Banco de Boston.

Eshed, V., A. Gopher, A. y Hershkovitz, I. (2006). Tooth Wear and Dental Pathology at the Advent of Agriculture: New Evidence From the Levant. American Journal of Physical Anthropology, 130, 145-159.

Fajre, S. (2003). De Rosas a Sarmiento. Buenos Aires vida cotidiana. Buenos Aires: Secretaria de Cultura, Gobierno de Buenos Aires.

Figueroa, P. (2006). Los molinos hidráulicos en Mendoza (Argentina) durante el período colonial (S. XVI, XVII y XVIII). Revista Universum, 21(1), 1-24.

Gaitán Ammann, F. (2001-2002). Recordando a los Uribe. Memorias de higiene y de templanza en la Bogotá del Olimpo Radical (1870-1880). Revista de Antropología y Arqueologia. Volumen Especial. Objetos y relatos: estudios de cultura material, 13, 125-146.

García Laborde, P., Suby, J. A., Guichón, R. y Casarli, R. (2010). El antiguo cementerio de la Misión de Río Grande, Tierra del Fuego. Primeros resultados sobre patologías nutricionales-metabólicas e infecciosas. Revista Argentina de Antropología Biológica, 12(1), 57-69. 
García Llorca, J. (2003). Avances en los estudios zooarqueológicos del sitio Escobería, en la manzana de Santo Domingo, Ciudad de Mendoza. Relaciones, 28, 133-152. Sociedad Argentina de Antropología. Buenos Aires.

Giamportone, T. A. (1998). Mendoza a través de los viajeros 1820-1850. En Cueto, A. y Ceverino, V. (Eds.). Los Hombres y las Ideas en la Historia de Cuyo (pp. 193-213), Tomo II. Facultad de Filosofía y Letras de la Universidad Nacional de Cuyo.

Giannotti, P. S. (2016a). Marcadores de estrés ocupacional en poblaciones históricas del norte de Mendoza (s. XVIXIX): primeros resultados exploratorios. Comechingonia. Revista de Arqueología, 20(1), 81-100.

Giannotti, P. S. (2016b). Aproximación a las condiciones de salud en la sociedad estamental mendocina a partir del análisis bioarqueológico: templo La Caridad (s. XVIIIXIX). Revista de Arqueología Histórica Argentina y Latinoamericana. En prensa.

Giannotti, S. y D. Mansegosa, D. (2011). Evaluación de indicadores sexuales y de edad de muerte de una muestra bioarqueológica del templo colonial La Caridad (Mendoza). En Calisaya, A. D. (Ed.). Arqueogasta. Estudiando el pasado...repensando el futuro. Actas del XII Congreso Nacional de Estudiantes de Arqueología (pp. 41-43). Tucumán.

Hartles, R., y Leach, S. (1975). Effect of diet on dental caries. British Medical Bulletin, 31, 137-141.

Henríquez Urzúa, M., y Prado Berlien, C. (2010). Patrón de desgaste, patologías dentarias y líneas hipoplásicas del esmalte en el bajo pueblo de Santiago del 1800: el caso del Cementerio la Pampilla. En Actas XVII Congreso Nacional de Arqueología Chilena Valdivia, Actas/2 (pp. 979. 988). Valdivia.

Hillson, S. (2001). Recording dental caries in archaeological human remains. International Journal Osteoarchaeology, 11, 249-289.

Hillson, S. (2008). The current state of dental decay. En Irish, J. D. y Nelson, G. C. (Eds.). Technique and application in dental anthropology, (pp. 111-135) Cambridge: Cambridge University Press.
Hubbe, M., Torres-Rouff, C., Neves, W. A., King, L. M., Da-Gloria, P. y Costa, M. A. (2012). Dental Health in Northern Chile's Atacama Oases: Evaluating the Middle Horizon (AD 500-1000) Impact on Local Diet. American Journal of Physical Anthropology, 148, 62-72.

Juengst, S. L., Chávez, S. J., Hutchinson, D. L. y Chávez, S. R. (2016). Late Preceramic Forager-Herders from the Copacabana Peninsula in the Titicaca Basin of Bolivia: A Bioarchaeological Analysis. International Journal of Osteoarchaeology. DOI: 10.1002/oa.2566

Larsen, C. S. (2015). Bioarchaeology: Interpreting Behavior from the Human Skeleton, 2nd ed., Cambridge: Cambridge University Press.

Larsen, C. S. (2002). Bioarchaeology: The Lives and Lifestyles of Past People. Journal of Archaeological Research, 10(2), 119-166.

Larsen, C. S., Shavit, R. y Griffin, M. C. (1991). Dental caries evidence for dietary change: an archeological context. En Kelley, M. A. y Larsen, C. S. (Eds.). Advances in dental anthropology (pp. 178-202). New York: Wiley-Liss.

Leatherman, T., y Goodman, A. H. (1997). Expanding the Biocultural Synthesis: Toward a Biology of Poverty. American Journal of Physical Anthropology, 102, 1-3.

Lemos, J. (1897). Higienización y demografía de Mendoza. Buenos Aires: Imprenta, Litografía y Encuadernación de J. Peuser.

Lingström, P., Van Houte, J. y Kasuya, T. (2000). Food starches and dental caries. Critical Reviews in Oral Biology and Medicine, 11, 366-80.

Lukacs, J. R. (1992). Dental pathology and agricultural intensification in South Asia new evidence from Bronce Age Harappa. American Journal Physical Anthropology, 87, 133-150.

Lukacs, J., y Largaespada, L. (2006). Explaining Sex Differences in Dental Caries Prevalence: Saliva, Hormones, and "Life-History" Etiologies. American Journal of $\mathrm{Hu}$ man Biology, 18, 540-555. 
Maferra, L. (2016). Arqueobotánica del norte de Mendoza: interpretaciones sobre el rol de los vegetales en la interacción indigena-hispana durante los siglos XVI y XVII. Serie Publicaciones del CIRSF, 9. Facultad de Filosofía y Letras de la Universidad Nacional de Cuyo, Mendoza.

Mansegosa, D. (2010). Estudios bioarqueológicos en un templo colonial de Mendoza: La Caridad. En Actas del XVII Congreso Nacional de Arqueología Argentina (pp. 1777-1782), Tomo V. Facultad Filosofía y Letras de la Universidad Nacional de Cuyo.

Mansegosa, D. (2015a). Patrones de variación morfológica en poblaciones históricas del norte mendocino: aportes para el estudio del proceso de conquista y consolidación colonial. Tesis doctoral inédita. Universidad Nacional de La Plata.

Mansegosa, D. (2015b).Variación morfológica postcraneal en poblaciones históricas del norte de Mendoza: análisis de la relación entre la estatura y el índice de platimería. En Libro de resumenes de las XXIV Jornadas de Investigación y VI Jornadas de Posgrado (p. 45). Universidad Nacional de Cuyo, Mendoza.

Mansegosa, D. (2016). Estudios sobre salud y enfermedad en poblaciones históricas urbanas de Mendoza (Argentina). Nuevos aportes para el estudio bioarqueológico de La Caridad. Comechingonia virtual Revista de Arqueología, 20(1), 111-142.

Mansegosa, D., Gámez Mendoza, A. y Giannotti, P. S. (2014). Perfil de mortalidad de una muestra bioantropológica del templo de La Caridad (Mendoza). En Luna, L., Aranda, C. y Suby, J. (Eds.). Avances recientes en la bioarqueología latinoamericana (pp. 187-204). Buenos Aires: Grupo de Investigación en Bioarqueología (GIB).

Mansegosa, D. y Chiavazza, H. (2010). Consecuencias del proceso de colonización en la salud de la población urbana de Mendoza (Argentina): un estudio desde evidencias paleopatológicas (S. XVIII-XIX). Revista Española de Paleopatologia, 8, 1-18.

Mansegosa, D. y Giannotti, S. (2015). Aportes metodológicos para estimar la edad de muerte a partir del grado de desgaste dental en poblaciones históricas de Mendoza. En Libro de resúmenes del VI Congreso Nacional de Arqueología Histórica (pp. 166-167). Facultad de Filosofía y Letras de la Universidad Nacional de Cuyo, Mendoza.
Menéndez, L. P. (2016). Spatial Variation of Dental Caries in Late Holocene Samples of Southern South America: A Geostatistical Study. American Journal Of Human Biology. DOI: 10.1002/ajhb.22874.

Novellino, P., Gil, A., Neme, G. y Durán, V. (2004). El consumo de maíz en el Holoceno Tardío del Oeste Argentino: Isótopos estables y Caries. Revista Española de Antropología Americana, 34, 85-110.

Ortega, C., Hernández, F. y Barbosa, D. (2006). Estudios zooarqueológicos del predio mercedario del área fundacional de Mendoza. En Chiavazza, H. y Zorrilla, V. (Eds.). Arqueología en el predio mercedario de la ciudad de Mendoza (pp. 79-120). Facultad Filosofía y Letras de la Universidad Nacional de Cuyo. Mendoza.

Prieto, M. R. (2000 [1983]). Formación y consolidación de una sociedad en un área marginal del Reino de Chile: la Provincia de Cuyo en el siglo XVII. Tesis doctoral, Universidad de Sevilla. Anales del Instituto de Arqueología y Etnologia, 52-53, 18-366.

Ribeiro, C. C., Tabchoury, C. P., Del Bel Cury, A. A., Tenuta, L. M., Rosalen, P. L. y Cury, J. A. (2005). Effect of starch on the cariogenic potential of sucrose. British Journal of Nutrition, 94, 44-50.

Rodríguez, A., González, C. y Henríquez, M. (2004). Arqueología histórica en la parroquia La Purísima Concepción de Colina. Región metropolitana. Chungara. Revista de Antropología Chilena, 36(1), 117-129.

Sampieri, R. H., COLLADO, C. F. y Lucio, P. B. (1991). Metodologia de la Investigación. México: McGraw Hill.

Semorile, A., Martín de Codoni, E., Cano Rossini, L., Puig López, M. y Laria, S. (1988). Historia de la medicina de Mendoza. Tomo I y II. Mendoza. ¿Editorial?

Turner, C. G. II (1979). Dental anthropological indications of agricultura among the Jomon people of central Japan. American Journal Physical Anthropology, 51, 619-636.

Turner, L. B. (2013). Interpreting oral pathology at Machu Picchu, Peru. International Journal of Osteoarchaeology, 25, 502-514. 
Valdenegro, R., Caro, C., Cruz, R., Díaz, S., Peters, E. y Ramírez, H. (2014). Historia de la educación universitaria en Odontología y rol social de los cirujanos dentistas en Chile. Revista de Educación y Ciencia de la Salud, 11(1), 54-60.

Vega Lizama, E., y Cucina, A. (2001). Las patologías orales: caries, abscesos y pérdida de dientes en vida. En Cucina, A. (Ed.). Manual de Antropología Dental (pp. 107-130). México: Ediciones de la Universidad Autónoma de Yucatán.
Verdaguer, J. (1931). Historia Eclesiástica de Cuyo. Tipografía Saleciana, Milano. Tomo I y II. Mendoza.

Vieira, A. R. (2012). Genetics and Caries - Perspectives. Brazilian Oral Research 26(Suppl 1), 7-9.

Wasterlain, S., Hillson, S. y Cunha, E. (2009). Dental Caries in a Portuguese Identified Skeletal Sample From the Late 19th and Early 20th Centuries. American Journal of Physical Anthropology, 140, 64-79. 